\title{
The dexmedetomidine concentration required after remifentanil anesthesia is three-fold higher than that after fentanyl anesthesia or that for general sedation in the ICU
}

\author{
This article was published in the following Dove Press journal: \\ Therapeutics and Clinical Risk Management \\ 4 October 2014 \\ Number of times this article has been viewed
}

\author{
Takayuki Kunisawa' \\ Kazuhiro Fujimoto ${ }^{2}$ \\ Atsushi Kurosawa ${ }^{2}$ \\ Michio Nagashima ${ }^{2}$ \\ Koji Matsui ${ }^{2}$ \\ Dai Hayashi ${ }^{2}$ \\ Kunihiko Yamamoto ${ }^{2}$ \\ Yuya Goto ${ }^{2}$ \\ Hiroaki Akutsu ${ }^{3}$ \\ Hiroshi Iwasaki \\ 'Surgical Operation Department, \\ Asahikawa Medical University \\ Hospital, ${ }^{2}$ Department of \\ Anesthesiology and Critical Care \\ Medicine, ${ }^{3}$ Central Laboratory for \\ Research and Education, Asahikawa \\ Medical University, Asahikawa, \\ Hokkaido, Japan
}

Purpose: The general dexmedetomidine (DEX) concentration required for sedation of intensive care unit patients is considered to be approximately $0.7 \mathrm{ng} / \mathrm{mL}$. However, higher DEX concentrations are considered to be required for sedation and/or pain management after major surgery using remifentanil. We determined the DEX concentration required after major surgery by using a target-controlled infusion (TCI) system for DEX.

Methods: Fourteen patients undergoing surgery for abdominal aortic aneurysms (AAA) were randomly, double-blindly assigned to two groups and underwent fentanyl- or remifentanilbased anesthetic management. DEX TCI was started at the time of closing the peritoneum and continued for 12 hours after stopping propofol administration (M0); DEX TCI was adjusted according to the sedation score and complaints of pain. The doses and concentrations of all anesthetics and postoperative conditions were investigated.

Results: Throughout the observation period, the predicted plasma concentration of DEX in the fentanyl group was stable at approximately $0.7 \mathrm{ng} / \mathrm{mL}$. In contrast, the predicted plasma concentration of DEX in the remifentanil group rapidly increased and stabilized at approximately $2 \mathrm{ng} / \mathrm{mL}$. The actual DEX concentration at 540 minutes after M0 showed a similar trend $(0.54 \pm 0.14$ [fentanyl] versus $1.57 \pm 0.39 \mathrm{ng} / \mathrm{mL}$ [remifentanil]). In the remifentanil group, the dopamine dose required and the duration of intubation decreased, and urine output increased; however, no other outcomes improved.

Conclusion: The DEX concentration required after AAA surgery with remifentanil was three-fold higher than that required after AAA surgery with fentanyl or the conventional DEX concentration for sedation. High DEX concentration after remifentanil affords some benefits in anesthetic management.

Keywords: plasma concentration, effect-site concentration (ESC), target-controlled infusion (TCI), abdominal aortic aneurysms (AAA), dopamine, urine output

\section{Introduction}

The plasma concentration (Cp) of dexmedetomidine (DEX) usually required for sedation in patients admitted to the intensive care unit (ICU) is approximately $0.7 \mathrm{ng} / \mathrm{mL}{ }^{1}$ However, since postoperative management depends on the persistence of narcotic drugs in the body and the size of surgical invasiveness, the concentration of DEX required for sedation and/or pain management might vary, which is also suggested by the following findings of previous studies on DEX. In many cases, administration of propofol and morphine for sedation and pain management, respectively, were reported to be required in addition to the administration of the conventional DEX dose, which
Correspondence: Takayuki Kunisaw Department of Anesthesiology and Critical Care Medicine, Asahikawa Medical University 2-I-I-I Midorigaoka-higashi, Asahikawa, Hokkaido 07885 I0, Japan

Tel $+8 \mid 166682583$

Fax +8I I66 682589

Email taka.kunisawa@nifty.ne.jp 
indicated that the administration of the conventional DEX dose alone cannot induce an adequate effect in some cases. ${ }^{2,3}$ A wide range of DEX doses to achieve the adequate effect has also been reported to be required in previous studies. ${ }^{4-6}$ In some cases, high doses of DEX were required when DEX was administered as the sole agent for sedation and/or pain management in patients undergoing invasive procedures. ${ }^{7-12}$ All of the abovementioned findings suggest that different concentrations of DEX may be required for sedation and/or pain management in different cases. Moreover, since no study has reported the DEX concentration required after surgery managed using fixed anesthetics, the optimal concentration of DEX required for sedation or pain management is yet to be determined. Therefore, we investigated the concentration of DEX required for postoperative management after surgery for abdominal aortic aneurysms (AAAs); the postoperative management was performed using the fixed anesthetic method with target-controlled infusion (TCI) of DEX, in which narcotic drugs can be changed because it is assumed that one of them, remifentanil (REM), whose effect rapidly was eliminated, can easily affect the required DEX concentration.

\section{Materials and methods Patients}

The study was approved and monitored by the Research Ethics Committee of Asahikawa Medical University and registered with the University hospital Medical Information Network Center clinical trial registry (UMIN000003901). Written informed consent was obtained from each patient. The study population consisted of 14 patients (aged 64-86 years) who were scheduled to undergo surgery for AAA. Exclusion criteria were severe cardiovascular disease (New York Heart Association class 4 or less than $30 \%$ left ventricular ejection fraction) or concurrent systemic disorders (eg, severe liver dysfunction or renal failure on hemodialysis). Patients with arrhythmias characterized by atrial fibrillation or disturbance in the conduction system, and those receiving $\alpha$-methyldopa or clonidine treatment were also excluded from this study. The 14 patients were assigned to two groups, namely, the fentanyl (FEN) group and REM group. This study was controlled, double-blinded, and randomized using the sealed-envelope technique.

\section{Anesthetic management}

An epidural catheter was placed via the Th12-L1 intervertebral space for administering late postoperative analgesia after stopping DEX administration. The patients were not administered any premedication. During general anesthesia in the operating room (OR), atrial pressure monitoring in addition to standard monitoring were performed using IntelliVue M8010A (Philips Electronics Japan, Ltd, Tokyo, Japan). Anesthesia was induced and maintained using TCI of propofol and FEN or REM. Propofol was administered using a syringe pump (TE-371; Terumo Corporation, Tokyo, Japan) with a built-in diprifusor ${ }^{\circledR}$ (AstraZeneca plc, London, UK). FEN and REM were administered via effect-site TCI using a syringe pump (Graseby ${ }^{\text {TM }}$ 3500; Graseby Medical Ltd, Watford, UK) controlled using STANPUMP software (available at: http://opentci.org/doku.php; accessed March 1, 2010) according to the pharmacokinetic parameters described by Shafer et al or those described by Minto et al. ${ }^{13,14}$ The target concentration of propofol was adjusted to maintain a constant bispectral index (BIS) value (BIS monitor $^{\circledR}$; Nihon Kohden Corporation, Tokyo, Japan) in the range 40-60. FEN and REM were adjusted to maintain the heart rate (HR) in the range $50-80 \mathrm{bpm}$. The syringes containing the narcotic drugs were prepared by an anesthesiologist and were labeled only with the study identification number. Another anesthesiologist, who was blinded to the syringe contents during the study, adjusted the target effect-site concentration (ESC) of the narcotic drugs. In accordance with the parameter described by Dyck et al, ${ }^{15}$ DEX administration was started at the time of closing the peritoneum at the target $\mathrm{Cp}$ of $0.7 \mathrm{ng} / \mathrm{mL}$; this administration was performed using the same system used for administering the narcotic drugs. Administration of narcotics was stopped immediately after the completion of surgery. Propofol administration was stopped at the time of transferring the patients from the OR to the ICU, and this time was defined as M0; patients were administered TCI of DEX while being transferred to the ICU.

\section{Post-anesthetic management}

In addition to standard monitoring in the ICU, atrial pressure and BIS value were monitored as in the OR. DEX doses were adjusted to maintain a Ramsay sedation score $(\mathrm{RSS})^{16}$ of 3-5 during intubation and 2-5 after extubation in the ICU by an intensivist who remained blinded to the type of narcotic drugs used for anesthetic management. The target concentration of DEX was increased when the patients complained of pain. The patients were weaned off the respirator if they satisfied standard criteria, ${ }^{17}$ and the fraction of inspired oxygen $\left(\mathrm{FiO}_{2}\right)$ was adjusted to maintain the pulse oximetry oxygen saturation $\left(\mathrm{SpO}_{2}\right)$ at more than $96 \%$. Three cardiovascular drugs - dopamine (DOA; minimal 
dose, $1 \mu \mathrm{g} / \mathrm{kg} \cdot \mathrm{min}$ ), nitroglycerine (NTG; minimal dose, $0.1 \mu \mathrm{g} / \mathrm{kg} \cdot \mathrm{min})$, and prostaglandin $\mathrm{E} 1$ ( $\mathrm{PGE}_{1}$; minimal dose, $0.005 \mu \mathrm{g} / \mathrm{kg} \cdot \mathrm{min}$ ) - were administered as part of our routine institutional procedure for the preservation of renal, coronary, and peripheral circulation, respectively. These drug doses were adjusted to maintain the systolic blood pressure (SBP) within the range $90-140 \mathrm{mmHg}$. Administration of DEX was stopped 12 hours after stopping propofol administration (M720), and $50 \mathrm{mg}$ of $1 \%$ xylocaine was administered into the epidural space for late post-analgesic management, followed by its continuous infusion at a dose of $5 \mathrm{~mL} / \mathrm{h}$.

\section{Data collection}

SBP, diastolic blood pressure, and HR were measured as hemodynamic parameters. The doses of DOA, NTG, and $\mathrm{PGE}_{1}$, which were administered as cardiovascular drugs, were recorded. Respiration rate (RR), $\mathrm{SpO}_{2}$, and $\mathrm{FiO}_{2}$ were measured as respiratory parameters. RSS, BIS value, and the Richmond Sedation and Agitation Scale (RASS) ${ }^{18}$ were measured to determine the degree of sedation. The amounts and concentrations of FEN, REM, and DEX were recorded from the $\log$ of the STANPUMP software. The time required for extubation, duration of bed rest, and the time required to start drinking and eating were recorded.

\section{Measurement of $C_{p}$}

Blood samples were collected for measurement of $\mathrm{Cp}$ at 540 minutes after M0 (M540) after ensuring that the target concentration was maintained and that the syringe used for administration remained unchanged for over 15 minutes; thus, we aimed to ensure a steady state during blood sampling. The blood samples were centrifuged, and plasma was frozen and stored at $-80^{\circ} \mathrm{C}$ until further analysis. $\mathrm{Cp}$ of DEX was measured by making a few modifications to a previously described method: ${ }^{19,20}$ the amount of detomidine and $0.5 \%$ pentafluorobenzoyl chloride was increased to $10 \mathrm{ng} / \mathrm{mL}$ and $10 \mu \mathrm{L}$, respectively, and that of toluene was decreased to $50 \mu \mathrm{L}$. Gas chromatography-mass spectrography involving positive ion mode electron ionization was performed by using JMS-SX102QQ (JEOL, Tokyo, Japan) using an Ultra ALLOY-1 (Frontier Laboratories, Ltd, Fukushima, Japan) column. The retention times for DEX and detomidine were 4.81 and 4.72 minutes, respectively.

\section{Statistical analysis}

Differences in sex and the American Society of Anesthesiologists-physical status scores were analyzed using the Mann-Whitney $U$ test. The other demographic parameters, amount and ESC of anesthetics, body fluid balance, total amount of DEX, measured Cp of DEX, the time required for extubation, duration of bed rest, and the time required to start drinking and eating, were analyzed using an unpaired $t$-test. The hemodynamic parameter values, BIS value, $\mathrm{RR}, \mathrm{SpO}_{2}, \mathrm{FiO}_{2}$, and the amount of cardiovascular drugs administered were analyzed using a repeatedmeasures analysis of variance (ANOVA) followed by the unpaired $t$-test or Mann-Whitney $U$ test as a post hoc test for determining intergroup differences at the same time points. Persistent ESC of narcotic drugs and predicted Cp of DEX were analyzed using ANOVA followed by Dunnett's test for comparison with the corresponding values at $\mathrm{M} 0$ in the same group, and using the unpaired $t$-test determining intergroup differences at the same time points. Data were expressed in terms of mean \pm standard deviation (SD), and a $P$-value less than 0.05 was considered statistically significant. Since no similar previous controlled study has been reported, power analysis was performed using the maximum values in eleven cases from six case reports in which DEX was administered at high doses as the sole agent for noxious treatment, ${ }^{8-12,21}$ and the revised data reported by Kamibayashi and Maze ${ }^{1}$ (assuming that $\mathrm{n}=11 ; \mathrm{SD}=50 \%$ of the average) by using G*Power 3 (available at: http://www.psycho.uni-duesseldorf. de/abteilungen/aap/gpower3/; accessed March 1, 2010) was used for calculating power. Recruitment of ten patients was required to detect the differences in DEX concentration in a situation in which DEX administration at high doses was required for sedation, and a situation in which standard DEX administration was required. The study power (0.86) was determined on the basis of effect size (intergroup difference in predicted Cps at 720 minutes) of $1.8 \mathrm{ng} / \mathrm{mL} \mathrm{SD}=0.038$ for the FEN group and SD $=1.038$ for the REM group $(n=7$ per group and $\alpha=0.05$ ).

\section{Results}

\section{Patient demographics and anesthetic management}

The patients' demographic characteristics and data on anesthetic management are shown in Table 1. No intergroup differences were observed with regard to patients' demographics. Furthermore, there were no intergroup differences with regard to duration of surgery, anesthetic management, body fluid balances, sex ratio, and ratio of the adopted surgical approach. The total amount of FEN administered to the patients in the FEN group in the OR $(1.56 \pm 0.33 \mathrm{mg})$ was lower than that of REM administered to the patients in the REM group $(7.42 \pm 1.98 \mathrm{mg})$. The mean ESC of FEN in the 
Table I Patient demographic and anesthetic management characteristics

\begin{tabular}{|c|c|c|c|}
\hline & $\begin{array}{l}\text { FEN } \\
\text { group }\end{array}$ & $\begin{array}{l}\text { REM } \\
\text { group }\end{array}$ & $P$-value \\
\hline Number of patients & 7 & 7 & - \\
\hline Age, years & $70 \pm 9$ & $73 \pm 6$ & 0.525 \\
\hline Sex, male/female & $5 / 2$ & $6 / 1$ & 0.530 \\
\hline Weight, kg & $63 \pm 10$ & $57 \pm 8$ & 0.203 \\
\hline Height, cm & $161 \pm 9$ & $156 \pm 7$ & 0.287 \\
\hline ASA PS (II/III) & $4 / 3$ & $5 / 2$ & 0.591 \\
\hline Duration of surgery, minutes & $400 \pm 124$ & $322 \pm 48$ & 0.150 \\
\hline $\begin{array}{l}\text { Duration of anesthetic } \\
\text { management, minutes }\end{array}$ & $515 \pm 119$ & $442 \pm 55$ & 0.168 \\
\hline Infused fluid, $\mathrm{mL}$ & $5,83 I \pm 3,096$ & $6,136 \pm 1,432$ & 0.817 \\
\hline Infused blood, $\mathrm{mL}$ & $891 \pm 903$ & $712 \pm 747$ & 0.693 \\
\hline Urine output, mL & $I, 740 \pm 1,3 \mid I$ & $2,177 \pm 1,707$ & 0.601 \\
\hline Blood loss, $\mathrm{mL}$ & $\mathrm{I}, 462 \pm 943$ & $933 \pm 358$ & 0.191 \\
\hline Surgical approach (TP/TR) & $5 / 2$ & $6 / 1$ & 0.591 \\
\hline $\begin{array}{l}\text { Total amount of FEN or REM } \\
\text { for anesthetic management, mg }\end{array}$ & $1.56 \pm 0.33$ & $7.42 \pm 1.98$ & $<0.00 I^{*}$ \\
\hline $\begin{array}{l}\text { Mean ESC of FEN or REM } \\
\text { during surgery, } \mathrm{ng} / \mathrm{mL}\end{array}$ & $3.17 \pm 0.33$ & $9.31 \pm 3.11$ & $<0.00 I^{*}$ \\
\hline
\end{tabular}

Notes: Data are presented in terms of mean $\pm S D$ or number of patients. $* P$-value less than 0.05 was considered statistically significant.

Abbreviations: ASA PS, American Society of Anesthesiologists physical status; ESC, effect-site concentration; FEN, fentanyl; REM, remifentanil; SD, standard deviation; TP, transperitoneal; TR, transretroperitoneal.

FEN group during surgery $(3.17 \pm 0.33 \mathrm{ng} / \mathrm{mL})$ was lower than the corresponding ESC of REM in the REM group $(9.31 \pm 3.11 \mathrm{ng} / \mathrm{mL})$.

\section{Predicted concentration of narcotic drugs and predicted and measured concentration of DEX}

Since the administration of narcotics was stopped immediately after surgery, ESC decreased with time, which has been shown as persistent ESC of narcotics in Figure 1A. The ESC of FEN decreased gently after surgery and remained at $0.71 \pm 0.10 \mathrm{ng} / \mathrm{mL}$ at 720 minutes after M0 (M720). In contrast, the ESC of REM decreased so rapidly that the ESC at 30 minutes after M0 (M30) was $0.17 \pm 0.07 \mathrm{ng} / \mathrm{mL}$, and it continued to decrease thereafter. The predicted and measured $\mathrm{Cps}$ of DEX are shown in Figure 1B. The predicted Cp of DEX in the FEN group was stable and remained at approximately $0.7 \mathrm{ng} / \mathrm{mL}$ at all time points. In contrast, the predicted $\mathrm{Cp}$ of DEX in the REM group increased immediately after M0 and reached the highest value $(2.43 \pm 2.40 \mathrm{ng} / \mathrm{mL})$ at 44 minutes, 10 seconds after M0. Thereafter, the $\mathrm{Cp}$ fluctuated between $1.46 \mathrm{ng} / \mathrm{mL}$ and the highest concentration and stabilized at approximately $2 \mathrm{ng} / \mathrm{mL}$ about 300 minutes after M0. The measured Cp of DEX in the REM group $(1.57 \pm 0.39 \mathrm{ng} / \mathrm{mL})$ was higher than that in the FEN group $(0.54 \pm 0.14 \mathrm{ng} / \mathrm{mL})$.

\section{Postoperative conditions}

Postoperative condition are shown in Table 2. Only three hemodynamic parameter values (SBP at M30 and HR at M30 and $\mathrm{M} 60$ ) in the REM group were higher than the corresponding values in the FEN group. Intergroup differences with regard to the doses of NTG and PGE 1 were not significant; however, the DOA doses at M60, M180, M360, M540, and M720 in the FEN group were higher than the corresponding values in the REM group. Intergroup differences with regard to $\mathrm{SpO}_{2}$ and $\mathrm{FiO}_{2}$ were not significant; however, RR at M180, M360, and M540 in the REM group was higher than the corresponding values in the FEN group. The degrees of sedation, which were indicated by the RSS, BIS value, and RASS score, at M360, M540, and M720 in the REM group were greater than the corresponding values in the FEN group. Intergroup differences with regard to fluid infusion, blood transfusion, and blood loss were not significant; however, the urine output in the REM group $(146 \pm 44 \mathrm{~mL} / \mathrm{h})$ was higher than that in the FEN group $(91 \pm 27 \mathrm{~mL} / \mathrm{h})$. The total amount of DEX administered to the patients in the FEN group (319 $\pm 31 \mathrm{mg}$ ) was lower than that administered to the patients in the REM group (746 $\pm 362 \mathrm{mg}$ ). Furthermore, the time required for extubation in the REM group ( $92 \pm 51$ minutes) was shorter than that in the FEN group (171 \pm 75 minutes). Intergroup differences in the duration of bed rest and the time required to start drinking and eating were not significant.

\section{Discussion}

\section{Required concentration of DEX}

Many studies have reported the usefulness of administration of DEX at high doses since Ramsay and Luterman first reported the usefulness of DEX administration for surgery in patients in which airway management is potentially difficult. ${ }^{7-}$ ${ }^{12,21}$ Administration of rescue sedatives and analgesics was required in a controlled study in which conventional doses of DEX were administered; ${ }^{2,3}$ many controlled studies in which DEX was administered at high doses for intervention have been reported. ${ }^{4-6}$ Moreover, since REM is an ultra-shortacting narcotic, it was easy to assume that the required dose of DEX in patients who have undergone surgery with REM might be greater than that required in patients who have undergone surgery with FEN. In the present study, the Cp of REM decreased to $0.17 \pm 0.07 \mathrm{ng} / \mathrm{mL}$ at $\mathrm{M} 30$, while that of DEX increased to $2.21 \pm 2.36 \mathrm{ng} / \mathrm{mL}$. This finding indicates that postoperative analgesia was entirely induced by DEX, and the required dose and concentration of DEX were higher than the conventional values required for sedation. Our study revealed that three-fold higher DEX concentrations, in terms of both target and measured concentrations, might be required 

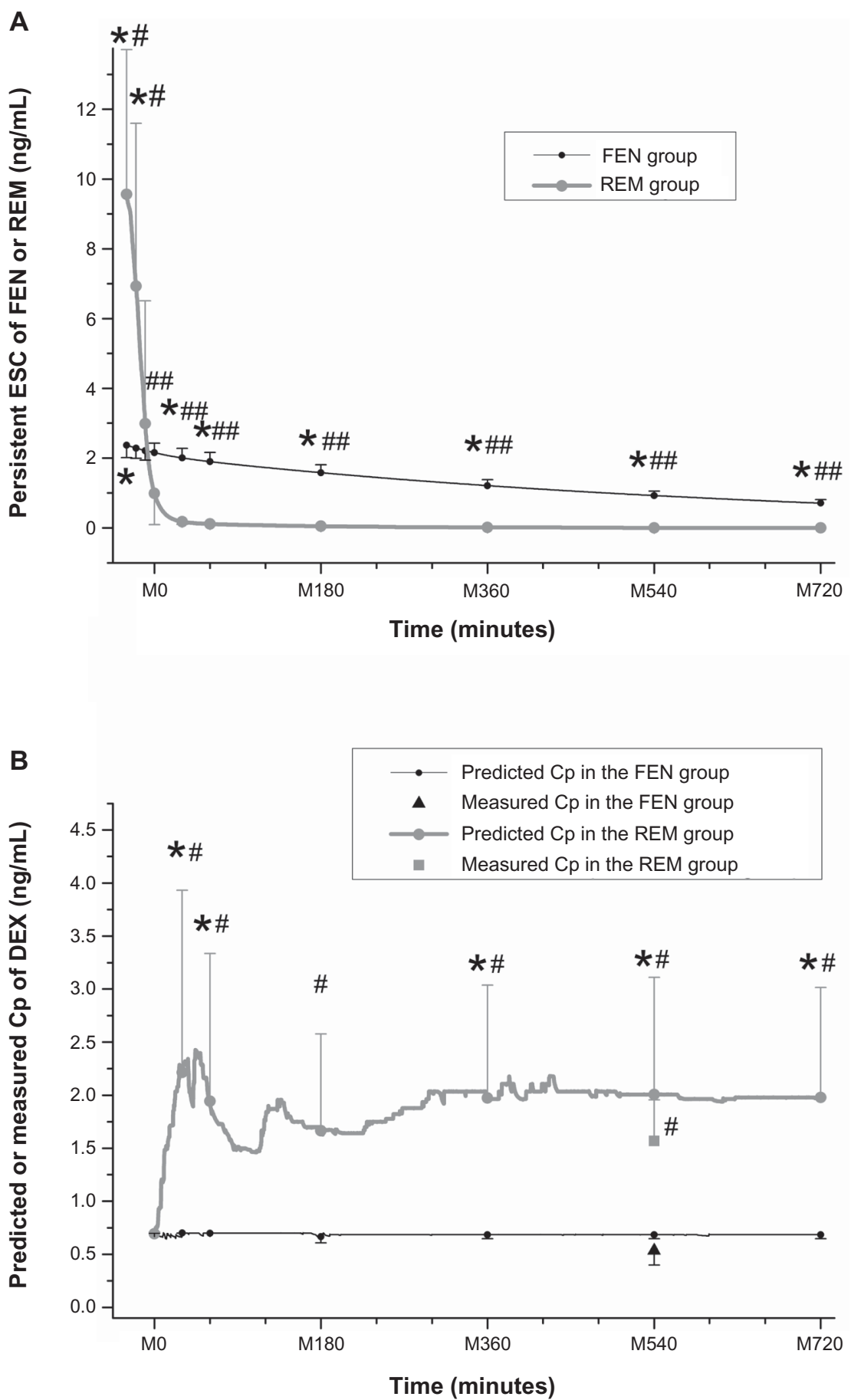

Figure I Persistent ESC of FEN or REM, and predicted or measured CP of DEX.

Notes: (A) Persistent ESC of FEN or REM. The ESCs of the narcotics - FEN and REM - decreased with time because administration of the narcotics was stopped immediately after surgery. The ESC of REM decreased very quickly after surgery: at MO (when the patient was being transferred from the operating room to the intensive care unit), the ESC had decreased to $1.00 \pm 0.89 \mathrm{ng} / \mathrm{mL}$; thereafter, the ESC continued to decrease and converged at $0 \mathrm{ng} / \mathrm{mL}$, in contrast to a gentle slope of decrease in the case of FEN. The ESC of FEN at M720 remained at $0.7 \mathrm{I} \pm 0.1 \mathrm{ng} / \mathrm{mL}$. The ESCs of REM 30 and 20 minutes before M0 (M-30 and M-20) in the REM group were higher than the corresponding ESCs of FEN in the FEN group. The ESCs of FEN at MO-M720 in the FEN group were higher than the corresponding ESCs of REM in the REM group. In the REM group, the ESCs of REM at M-30 and M-20 were higher than at M0. In the FEN group, the ESC of FEN at M-30 was higher than at M0, and those at M30-720 were lower than at MO. (B) Predicted or measured CP of DEX. The predicted $C_{p}$ of DEX in the FEN group was stable at approximately $0.7 \mathrm{ng} / \mathrm{mL}$ at all time points. In the FEN group, there were no significant differences between the predicted Cp of DEX at M0 and those at M30-720. The predicted Cp of DEX in the REM group increased immediately after the start of postoperative management, fluctuated, and stabilized at approximately 300 minutes after MO. In the REM group, the predicted CPs of DEX at all time points other than MI80 were higher than that at MO. The predicted CPs of DEX in the REM group were higher than the corresponding values in the FEN group at all time points (M30, M60, MI80, M360, M540, and M720) except M0. The measured CPs of DEX at M540 in the REM group were higher than the corresponding values in the FEN group. Data are expressed in terms of mean $\pm S D$; $* P<0.05$, when compared with the value at M0 in the same group; ${ }^{*}<<0.05$, when compared with the corresponding value in the FEN group; $\# P<0.05$, when compared with the corresponding value in the REM group.

Abbreviations: CP, plasma concentration; DEX, dexmedetomidine; ESC, effect-site concentration; FEN, fentanyl; M0-M720, 0-720 minutes; REM, remifentanil; SD, standard deviation. 
Table 2 Postoperative condition, total amount of DEX, and recovery time

\begin{tabular}{|c|c|c|c|c|c|c|c|c|c|c|}
\hline & \multicolumn{10}{|c|}{$<$ Hemodynamics $>$} \\
\hline & \multicolumn{7}{|c|}{ SBP $(\mathbf{m m H g})$} & \multicolumn{3}{|c|}{ DBP (mmHg) } \\
\hline & Mo & M30 & M60 & MI 80 & M360 & M540 & M720 & Mo & M30 & M60 \\
\hline FEN group & $111 \pm 30$ & $110 \pm 29$ & $116 \pm 18$ & $110 \pm 10$ & $111 \pm 17$ & $105 \pm 21$ & $103 \pm 11$ & $61 \pm 15$ & $65 \pm 19$ & $64 \pm 14$ \\
\hline REM group & $135 \pm 17$ & $137 \pm 14$ & $104 \pm 19$ & $123 \pm 18$ & $115 \pm 15$ & $108 \pm 16$ & $\|I I \pm\|$ & $70 \pm 16$ & $73 \pm 10$ & $61 \pm 10$ \\
\hline \multirow[t]{4}{*}{$P$-value } & 0.095 & $0.049 *$ & $0.25 I$ & 0.11 & 0.646 & 0.733 & 0.256 & 0.277 & 0.305 & 0.665 \\
\hline & \multicolumn{10}{|c|}{$<$ Respiratory system $>$} \\
\hline & \multicolumn{7}{|l|}{$\mathrm{SpO}_{2}(\%)$} & \multicolumn{3}{|l|}{ RR (bpm) } \\
\hline & Mo & M30 & M60 & MI 80 & M360 & M540 & M720 & Mo & M30 & M60 \\
\hline FEN group & $99.3 \pm 1.3$ & $98.6 \pm 1.4$ & $98.9 \pm 1.1$ & $98.6 \pm 1.5$ & $98.0 \pm 1.0$ & $98.4 \pm 1.3$ & $98.3 \pm 1.6$ & $12.0 \pm 1.7$ & $12.1 \pm 2.7$ & $13.0 \pm 3.4$ \\
\hline REM group & $99.1 \pm 1.2$ & $98.9 \pm 1.3$ & $97.3 \pm 2.4$ & $98.1 \pm 1.3$ & $99.0 \pm 1.5$ & $98.9 \pm 1.2$ & $98.6 \pm 1.3$ & $10.4 \pm 1.8$ & $16.4 \pm 6.0$ & $17.6 \pm 4.8$ \\
\hline \multirow[t]{4}{*}{$P$-value } & 0.832 & 0.704 & 0.135 & 0.586 & 0.173 & 0.531 & 0.718 & 0.123 & 0.110 & 0.061 \\
\hline & \multicolumn{10}{|c|}{$<$ Cardiovascular drugs $>$} \\
\hline & \multicolumn{7}{|c|}{ Dopamine $(\mu \mathrm{g} / \mathrm{kg} / \mathrm{min})$} & \multicolumn{3}{|c|}{ Nitroglycerin $(\mu \mathrm{g} / \mathrm{kg} / \mathrm{min})$} \\
\hline & Mo & M30 & M60 & MI80 & M360 & M540 & M720 & Mo & M30 & M60 \\
\hline FEN group & $2.25 \pm 0.89$ & $2.25 \pm 0.89$ & $2.25 \pm 0.89$ & $2.5 I \pm 0.82$ & $3.11 \pm 1.25$ & $3.10 \pm 1.00$ & $3.25 \pm 1.14$ & $0.16 \pm 0.04$ & $0.16 \pm 0.04$ & $0.16 \pm 0.04$ \\
\hline REM group & $1.42 \pm 0.57$ & $1.42 \pm 0.57$ & $1.20 \pm 0.25$ & $1.39 \pm 0.4 \mathrm{I}$ & $|.28 \pm 0.3|$ & $1.23 \pm 0.29$ & $1.69 \pm 63$ & $0.37 \pm 0.30$ & $0.37 \pm 0.30$ & $0.37 \pm 0.30$ \\
\hline \multirow[t]{4}{*}{$P$-value } & 0.057 & 0.057 & $0.010 *$ & $0.008 *$ & $0.003 *$ & $<0.001 *$ & $0.018 *$ & 0.095 & 0.095 & 0.089 \\
\hline & \multicolumn{10}{|c|}{$<$ Sedated condition $>$} \\
\hline & \multicolumn{7}{|c|}{ Ramsay sedation score } & \multicolumn{3}{|l|}{ BIS value } \\
\hline & Mo & M30 & M60 & MI80 & M360 & M540 & M720 & Mo & M30 & M60 \\
\hline FEN group & $6.0 \pm 0.0$ & $5.0 \pm 1.3$ & $4.0 \pm 1.4$ & $3.0 \pm 1.0$ & $2.3 \pm 0.5$ & 2. $1 \pm 0.4$ & $2.0 \pm 0.0$ & $58.7 \pm 11.5$ & $72.4 \pm 12.1$ & $76.6 \pm 12.9$ \\
\hline REM group & $6.0 \pm 0.0$ & $5.6 \pm 0.8$ & $4.4 \pm 1.3$ & $3.7 \pm 1.3$ & $3.6 \pm 0.8$ & $3.9 \pm 0.9$ & $3.0 \pm 1.0$ & $69.4 \pm 15.1$ & $61.4 \pm 18.1$ & $70.3 \pm 13.4$ \\
\hline \multirow[t]{4}{*}{$P$-value } & 1.000 & 0.482 & 0.565 & 0.307 & $0.009 *$ & $0.003 *$ & $0.025 *$ & 0.160 & 0.206 & 0.388 \\
\hline & & \multicolumn{9}{|c|}{$<$ Others $>$} \\
\hline & & \multicolumn{9}{|c|}{ Body fluid balance (1 2 hours) } \\
\hline & & \multicolumn{2}{|c|}{$\begin{array}{l}\text { Fluid infusion } \\
(\mathrm{mL} / \mathrm{h})\end{array}$} & \multicolumn{3}{|c|}{$\begin{array}{l}\text { Blood transfusion } \\
(\mathrm{mL} / \mathrm{h})\end{array}$} & \multicolumn{2}{|c|}{$\begin{array}{l}\text { Urine output } \\
(\mathrm{mL} / \mathrm{h})\end{array}$} & & $\begin{array}{l}\text { Blood loss } \\
(\mathrm{mL} / \mathrm{h})\end{array}$ \\
\hline FEN group & & \multicolumn{2}{|l|}{$158 \pm 22$} & \multicolumn{3}{|c|}{$17.3 \pm 29.6$} & \multicolumn{2}{|c|}{$91 \pm 27$} & & $12.0 \pm 10.4$ \\
\hline REM group & & \multicolumn{2}{|l|}{$150 \pm 43$} & \multicolumn{3}{|c|}{$10.0 \pm 18.4$} & \multicolumn{2}{|c|}{$146 \pm 44$} & & $13.2 \pm 7.0$ \\
\hline$P$-value & & \multicolumn{2}{|l|}{0.652} & \multicolumn{2}{|c|}{0.591} & & 0.01 & & & 0.805 \\
\hline
\end{tabular}

Notes: Data are presented in terms of mean \pm SD. ${ }^{*} P$-value less than 0.05 was considered statistically significant (bold).

Abbreviations: BIS, bispectral index; DBP, diastolic blood pressure; DEX, dexmedetomidine; Dr, drinking; Et, eating; Ex, extubation; FEN, fentanyl; GB, duration of bed rest; HR, heart rate; M0-M720, 0-720 minutes; REM, remifentanil; RR, respiratory rate; RT, required time; SBP, systolic blood pressure; SD, standard deviation; SpO ${ }_{2}$, Pulse oxygen oximeter saturation; $\mathrm{FiO}_{2}$, fraction of inspired oxygen; M0-M720, 0-720 minutes.

after REM anesthesia as compared to the DEX concentrations required after FEN anesthesia.

\section{Hemodynamics}

Among the hemodynamic parameters, SBP showed significant differences at M30 and HR showed significant differences at M30 and M60. These differences can be attributed to the rapid decrease in the effect of REM, which is indicated by the low ESC of REM at M30 and M60 (Figure 1A) and the high predicted $\mathrm{Cp}$ of DEX (Figure 1B). However, the intergroup differences in most of the hemodynamic parameters were not significant. Blood pressure data should be carefully interpreted during administration of DEX. DEX has two effects on blood pressure: DEX elevates blood pressure by causing vasoconstriction and decreases blood pressure by exerting a sympatholytic effect. ${ }^{22}$ Both predicted and measured Cps of DEX were approximately $1.5-2.0 \mathrm{ng} / \mathrm{mL}$ in the REM group and approximately $0.5-0.7 \mathrm{ng} / \mathrm{mL}$ in the FEN group, and both Cps of DEX in the REM and FEN groups were considered to be moderate (blood pressure was normal at these concentrations) and low (blood pressure tended to be low at these concentrations), respectively, on the basis of findings reported by Ebert et al. ${ }^{22}$ However, in the present study, intergroup differences in blood pressure at almost all time points were not significant, since blood pressure was maintained within a specific range by administering and adjusting the doses of cardiovascular drugs. Instead of that, the DOA doses administered at various time points to 


\begin{tabular}{|c|c|c|c|c|c|c|c|c|c|c|}
\hline \multirow[b]{2}{*}{ MI80 } & \multirow[b]{2}{*}{ M360 } & \multirow[b]{2}{*}{ M540 } & \multirow[b]{2}{*}{ M720 } & \multicolumn{7}{|c|}{ HR (bpm) } \\
\hline & & & & Mo & M30 & M60 & MI 80 & M360 & M540 & M720 \\
\hline $60 \pm 12$ & $57 \pm 17$ & $51 \pm 17$ & $52 \pm 8$ & $63 \pm 15$ & $61 \pm 11$ & $64 \pm 7$ & $67 \pm 8$ & $73 \pm 6$ & $7 I \pm 5$ & $73 \pm 8$ \\
\hline $59 \pm 12$ & $53 \pm 11$ & $52 \pm 9$ & $57 \pm 11$ & $76 \pm 10$ & $80 \pm 12$ & $75 \pm 10$ & $7 I \pm 20$ & $74 \pm 11$ & $74 \pm 7$ & $70 \pm 11$ \\
\hline \multirow[t]{2}{*}{0.914} & 0.609 & 0.880 & 0.363 & 0.064 & $0.008 *$ & $0.031 *$ & 0.654 & 0.789 & 0.388 & 0.499 \\
\hline & & & & \multicolumn{7}{|l|}{$\mathrm{FiO}_{2}$} \\
\hline MI80 & M360 & M540 & M720 & MO & M30 & M60 & MI80 & M360 & M540 & M720 \\
\hline $13.0 \pm 4.1$ & $13.4 \pm 3.8$ & $14.1 \pm 4.2$ & $15.4 \pm 5.4$ & $0.47 \pm 0.08$ & $0.50 \pm 0.12$ & $0.44 \pm 0.11$ & $0.37 \pm 0.05$ & $0.50 \pm 0.26$ & $0.40 \pm 0.12$ & $0.39 \pm 0.09$ \\
\hline $19.7 \pm 3.5$ & $\mid 8.7 \pm 1.7$ & $19.7 \pm 2.5$ & $18.7 \pm 4.2$ & $0.50 \pm 0.06$ & $0.49 \pm 0.04$ & $0.49 \pm 0.09$ & $0.43 \pm 0.13$ & $0.40 \pm 0.14$ & $0.36 \pm 0.11$ & $0.36 \pm 0.1 \mathrm{I}$ \\
\hline \multirow[t]{2}{*}{$0.006 *$} & $0.006 *$ & $0.011 *$ & 0.228 & 0.442 & 0.761 & 0.449 & 0.283 & 0.387 & 0.497 & 0.611 \\
\hline & & & & \multicolumn{7}{|c|}{ Prostaglandin $E_{1}$ (ng/kg/min) } \\
\hline MI80 & M360 & M540 & M720 & Mo & M30 & M60 & MI80 & M360 & M540 & M720 \\
\hline $0.14 \pm 0.04$ & $0.14 \pm 0.04$ & $0.14 \pm 0.04$ & $0.14 \pm 0.04$ & $7.86 \pm 3.57$ & $7.86 \pm 3.57$ & $7.86 \pm 3.57$ & $7.20 \pm 3.06$ & $6.38 \pm 1.76$ & $6.38 \pm 1.76$ & $6.38 \pm 1.76$ \\
\hline $0.25 \pm 0.13$ & $0.26 \pm 0.15$ & $0.21 \pm 0.08$ & $0.21 \pm 0.08$ & $9.04 \pm 1.62$ & $9.04 \pm 1.62$ & $|0.4 \pm 4.4|$ & $8.40 \pm 1.96$ & $8.40 \pm 1.96$ & $8.40 \pm 1.96$ & $8.40 \pm 1.96$ \\
\hline \multirow[t]{2}{*}{0.052} & 0.068 & 0.057 & 0.057 & $0.44 I$ & 0.441 & 0.257 & 0.400 & 0.065 & 0.065 & 0.065 \\
\hline & & & & \multicolumn{7}{|c|}{ Richmond sedation-agitation scale score } \\
\hline MI80 & M360 & M540 & M720 & MO & M30 & M60 & MI80 & M360 & M540 & M720 \\
\hline $86.9 \pm 8.7$ & $89.7 \pm 5.2$ & $89.3 \pm 7.4$ & $87.6 \pm 9.1$ & $-5.0 \pm 0.0$ & $-4.0 \pm 1.3$ & $-2.9 \pm 1.1$ & $-1.7 \pm 1.5$ & $-1.0 \pm 0.8$ & $-0.4 \pm 0.8$ & $-0.3 \pm 0.5$ \\
\hline $71.1 \pm 17.5$ & $77.1 \pm 8.5$ & $69.7 \pm 12.8$ & $72.6 \pm 11.1$ & $-5.0 \pm 0.0$ & $-4.6 \pm 0.5$ & $-3.7 \pm 0.8$ & $-2.7 \pm 1.4$ & $-2.7 \pm 1.3$ & $-2.4 \pm \mathrm{I} .4$ & $-2.1 \pm 1.2$ \\
\hline 0.055 & $0.006 *$ & $0.004^{*}$ & $0.017^{*}$ & 1.000 & 0.522 & 0.134 & 0.237 & $0.013 *$ & $0.007^{*}$ & $0.004 *$ \\
\hline \multicolumn{3}{|c|}{$\begin{array}{l}\text { Total amount of DEX } \\
\text { (mg) }\end{array}$} & \multicolumn{2}{|c|}{$\begin{array}{l}\text { RT to Ex } \\
\text { (min) }\end{array}$} & \multicolumn{2}{|c|}{$\begin{array}{l}\mathbf{R T} \text { to } \mathrm{GB} \\
\text { (days) }\end{array}$} & \multicolumn{3}{|c|}{$\begin{array}{l}\text { RT to } \mathrm{Dr} \\
\text { (days) }\end{array}$} & $\begin{array}{l}\text { RT to Et } \\
\text { (days) }\end{array}$ \\
\hline \multicolumn{3}{|l|}{$319 \pm 31$} & \multicolumn{2}{|l|}{$|7| \pm 75$} & \multicolumn{2}{|c|}{$4.9 \pm 2.2$} & \multicolumn{3}{|c|}{$3.0 \pm 1.6$} & $4.1 \pm 1.5$ \\
\hline \multicolumn{3}{|l|}{$746 \pm 362$} & \multicolumn{2}{|l|}{$92 \pm 51$} & \multicolumn{2}{|c|}{$3.0 \pm 1.9$} & \multicolumn{3}{|c|}{$3.7 \pm 1.4$} & $4.3 \pm 1.5$ \\
\hline \multicolumn{3}{|l|}{$0.009 *$} & \multicolumn{2}{|l|}{$0.039 *$} & \multicolumn{2}{|c|}{0.117} & \multicolumn{3}{|c|}{0.394} & 0.860 \\
\hline
\end{tabular}

the FEN group were higher than the corresponding doses administered to the REM group.

With regard to $\mathrm{HR}$, bradycardia was reported to be one of most important concerns in patients who were sedated with DEX in many studies. ${ }^{23,24}$ However, in this study, HR in the REM group at any time point was not lower than the corresponding value in the FEN group. This can be attributed to the fact that DOA, which is basically administered in all cases, prevented the occurrence of bradycardia, and adequate doses of FEN also tended to slow the HR.

\section{Respiratory system}

Respiratory problems such as desaturation or necessity of high $\mathrm{FiO}_{2}$ were not observed during postoperative management in both groups, and airway management and ventilation assistance were not required after extubation in both groups. These findings indicate that DEX administration usually does not affect the respiratory system in an adverse manner, even at high doses. However, there were intergroup differences with regard to RR at M180-M540. These differences can be attributed to the differences in the characteristics of DEX and FEN. DEX, which contributed to postoperative analgesia in the REM group, has been reported to increase RR when administered at a concentration greater than the target concentration, in a previous study, by $1.8 \mathrm{ng} / \mathrm{mL} .{ }^{25}$ In contrast, FEN, which contributed to postoperative analgesia in the FEN group, is known to decrease RR. 


\section{Sedation}

The degrees of sedation indicated by RSS, BIS value, and RASS score at M360-M720 in the REM group were greater than the corresponding values in the FEN group. This can be attributed to the fact that only DEX, which has a sedative effect, plays a role in alleviating pain after surgery in the REM group; in contrast, in the FEN group, the same role is played by FEN, which mainly has an analgesic effect. Administration of a high dose of DEX was required to alleviate pain in the REM group, which induced deep sedation. Ebert et al reported that DEX has some effects, such as a sympatholytic effect, and induces sedation and analgesia; that a dose-response relationship exists between DEX and each of its effects; and that the DEX concentration required for analgesia was greater than that required for sedation. ${ }^{22}$ Since postoperative analgesia is required following REM anesthesia, a high dose of DEX is required, which induces deep sedation.

\section{Others}

Intergroup differences in body fluid balances during surgery and in fluid infusion, blood transfusion, and blood loss after surgery were not significant. Moreover, the DOA doses at M60-M720 in the REM group were lower than the corresponding doses in the FEN group. However, the urine output after surgery in the REM group was greater than that in the FEN group. This finding can be attributed to the diuretic effect of DEX, which was described in a previous study in which the DEX group had significantly greater cumulative urine output at 4 and 12 hours after surgery than before surgery. ${ }^{26}$

Although administration of a high dose of DEX was required in the REM group, the time required for extubation in the REM group was shorter than that in the FEN group. This finding suggests that a high dose of DEX was not an impediment to weaning the patient off the ventilator compared with persistent FEN, supported by the fact that the administration of a high dose of DEX scarcely affected the respiratory system in a previous study. ${ }^{7,22}$ The combination of administration of REM during surgery and a high dose of DEX after surgery was found to facilitate extubation to a larger degree than that facilitated by the conventional combination of administration of FEN during surgery and a conventional dose of DEX after surgery. Persistence of FEN was also expected to affect the time required for the recovery of digestion as compared to DEX; however, significant intergroup differences in the time required to start drinking or eating were not observed. Moreover, significant intergroup differences with regard to duration of bed rest were not observed. This reason may be that the invasiveness of surgery and effect of surgery on gastrointestinal function were so large that the differences in perioperative management could not affect these outcomes. Therefore, we cannot mention the merit or demerits of outcome by means of the present result.

The measured Cps of DEX were lower than the predicted $\mathrm{Cp}$ of DEX. This finding can be attributed to the possibility that drug pharmacokinetics in our patients may not be similar to those in the healthy volunteers in a study with Dyck et al's parameter setting. ${ }^{15}$ However, we could not confirm this possibility because the sample size was inadequate for determining the drug pharmacokinetics. However, the ratio of measured Cp of DEX in the REM group to that in the FEN group is approximately three, and is similar to the ratio of predicted $\mathrm{Cp}$ in the REM group to that in the FEN group. Therefore, since it is obvious that the DEX concentration required after REM anesthesia is higher than that required after conventional anesthesia, higher doses of DEX are required after REM anesthesia.

\section{Limitations and future directions}

The limitations of this study are that the study population was limited to specific patients (elderly patients) who underwent a specific type of surgery (AAA surgery). Further studies may be required to determine the concentration of DEX required after other surgeries or in other patients. Moreover, FEN is also used in other clinical scenarios; for example, it is used for transitional analgesia while transferring a patient from the OR to the ICU; further studies are required to determine the optimal concentration of DEX in these scenarios. Further studies are required to determine many optimal concentrations of DEX for use in combination with FEN according to the type of surgery.

We found that the combination of the administration of REM during surgery and a high dose DEX after surgery increased the urine output after surgery and decreased the dose of DOA. However, this finding can be attributed to the effect of endogenic catecholamine released in response to stress or to the direct vasoconstrictive effect of DEX, since both of these effects can increase blood pressure and thereby result in a reduction in the dose of DOA and an increase in urine output. Since we did not measure the levels of stress hormones, we cannot specify the group that showed higher suppression of hormone release in response to stress. Therefore, we could not confirm the cause of the increased urine output and the decreased dose of DOA. Further studies 
should be conducted to determine the relationship between administration of a combination of narcotic drugs during surgery and DEX concentration required after surgery, and the stress hormone levels.

Moreover, although it was proven that the administration of high doses of DEX after REM anesthesia can shorten the time required for extubation without worsening the hemodynamic conditions or without causing adverse effects on the respiratory condition, improvement in other outcomes could not be confirmed. Further studies should be conducted to determine the combination of narcotics and the concentration of DEX that can improve other outcomes.

\section{Conclusion}

The patients who had undergone surgery for AAA were sedated using TCI of DEX following anesthetic management using two types of narcotics. The predicted and measured Cps of DEX in the REM group were approximately threefold higher than the corresponding values in the FEN group, because REM administered in the OR did not contribute to postoperative analgesia. Administration of high doses of DEX may be one of the methods for effective postoperative management after REM-based anesthetic management.

\section{Acknowledgments}

This work should be attributed to the Department of Anesthesiology and Critical Care Medicine, Asahikawa Medical University, Asahikawa, Hokkaido, Japan.

Financial support was provided solely by institutional and/or departmental sources. However, Hospira Japan (Osaka, Japan) and Orion Pharma (Turku, Finland), who had no involvement in the study, supplied detomidine and dexmedetomidine free-of-charge for measurement of drug concentration.

This work was presented at the 28th Annual Meeting of the Japan Society for Clinical Anesthesia in Kyoto, Japan on November 22, 2008.

The clinical trial registry identifier for this work is UMIN000003901.

\section{Disclosure}

The authors report no conflicts of interest in this work.

\section{References}

1. Kamibayashi T, Maze M. Clinical uses of alpha2 -adrenergic agonists. Anesthesiology. 2000;93(5):1345-1349.

2. Herr DL, Sum-Ping ST, England M. ICU sedation after coronary artery bypass graft surgery: dexmedetomidine-based versus propofol-based sedation regimens. J Cardiothorac Vasc Anesth. 2003;17(5):576-584.
3. Martin E, Ramsay G, Mantz J, Sum-Ping ST. The role of the alpha2adrenoceptor agonist dexmedetomidine in postsurgical sedation in the intensive care unit. J Intensive Care Med. 2003;18(1):29-41.

4. Tasdogan M, Memis D, Sut N, Yuksel M. Results of a pilot study on the effects of propofol and dexmedetomidine on inflammatory responses and intraabdominal pressure in severe sepsis. J Clin Anesth. 2009;21(6):394-400.

5. Venn RM, Grounds RM. Comparison between dexmedetomidine and propofol for sedation in the intensive care unit: patient and clinician perceptions. Br J Anaesth. 2001;87(5):684-690.

6. Ruokonen E, Parviainen I, Jakob SM, et al; "Dexmedetomidine for Continuous Sedation" Investigators. Dexmedetomidine versus propofol/ midazolam for long-term sedation during mechanical ventilation. Intensive Care Med. 2009;35(2):282-290.

7. Ramsay MA, Luterman DL. Dexmedetomidine as a total intravenous anesthetic agent. Anesthesiology. 2004;101(3):787-790.

8. Kunisawa T, Suzuki A, Takahata O, Iwasaki H. High dose of dexmedetomidine was useful for general anesthesia and post-operative analgesia in a patient with postpolio syndrome. Acta Anaesthesiol Scand. 2008;52(6):864-865.

9. Nagashima M, Kunisawa T, Takahata O, Iwasaki H. [Dexmedetomidine infusion for sedation during awake intubation]. Masui. 2008;57(6): 731-734. Japanese.

10. Kunisawa T, Nagata O, Ogasawara H, Ishio E, Takahata O, Iwasaki $\mathrm{H}$. [Anesthetic management of awake coronary artery bypass grafting using dexmedetomidine - high-dose administration and pharmacokinetic simulation]. Masui. 2006;55(10):1238-1242. Japanese.

11. Kunisawa $T$, Nagata $O$, Iwasaki H. [Pharmacokinetic simulation of high-dose administration of dexmedetomidine for decubitus treatment]. Masui. 2006;55(8):995-998. Japanese.

12. Kunisawa T, Ota M, Suzuki A, Takahata O, Iwasaki H. Combination of high-dose dexmedetomidine sedation and fascia iliaca compartment block for hip fracture surgery. J Clin Anesth. 2010;22(3): 196-200.

13. Shafer SL, Varvel JR, Aziz N, Scott JC. Pharmacokinetics of fentanyl administered by computer-controlled infusion pump. Anesthesiology. 1990;73(6):1091-1102.

14. Minto CF, Schnider TW, Egan TD, et al. Influence of age and gender on the pharmacokinetics and pharmacodynamics of remifentanil. I. Model development. Anesthesiology. 1997;86(1):10-23.

15. Dyck JB, Maze M, Haack C, Azarnoff DL, Vuorilehto L, Shafer SL. Computer-controlled infusion of intravenous dexmedetomidine hydrochloride in adult human volunteers. Anesthesiology. 1993; 78(5):821-828.

16. Ramsay MA, Savege TM, Simpson BR, Goodwin R. Controlled sedation with alphaxalone-alphadolone. Br Med J. 1974;2(5920):656-659.

17. AARC. AARC clinical practice guideline. Removal of the Endotracheal Tube -2007 revision and update. Respir Care. 2007; 52(1):81-93.

18. Sessler CN, Gosnell MS, Grap MJ, et al. The Richmond AgitationSedation Scale: validity and reliability in adult intensive care unit patients. Am J Respir Crit Care Med. 2002;166:1338-1344.

19. Vuorilehto L, Salonen JS, Anttila M. Picogram level determination of medetomidine in dog serum by capillary gas chromatography with negative ion chemical ionization mass spectrometry. J Chromatogr. 1989;497:282-287.

20. Dyck JB, Maze M, Haack C, Vuorilehto L, Shafer SL. The pharmacokinetics and hemodynamic effects of intravenous and intramuscular dexmedetomidine hydrochloride in adult human volunteers. Anesthesiology. 1993;78(5):813-820.

21. Kunisawa T, Nagashima M, Hanada S, Suzuki A, Takahata O, Iwasaki H. Awake intubation under sedation using target-controlled infusion of dexmedetomidine: five case reports. J Anesth. 2010;24(5): 789-792.

22. Ebert TJ, Hall JE, Barney JA, Uhrich TD, Colinco MD. The effects of increasing plasma concentrations of dexmedetomidine in humans. Anesthesiology. 2000;93(2):382-394. 
23. Biccard BM, Goga S, de Beurs J. Dexmedetomidine and cardiac protection for non-cardiac surgery: a meta-analysis of randomised controlled trials. Anaesthesia. 2008;63(1):4-14.

24. Carollo DS, Nossaman BD, Ramadhyani U. Dexmedetomidine: a review of clinical applications. Curr Opin Anaesthesiol. 2008;21(4): $457-461$.

25. Hsu YW, Cortinez LI, Robertson KM, et al. Dexmedetomidine pharmacodynamics: part I: crossover comparison of the respiratory effects of dexmedetomidine and remifentanil in healthy volunteers. Anesthesiology. 2004;101(5):1066-1076.
26. Frumento RJ, Logginidou HG, Wahlander S, Wagener G, Playford HR, Sladen RN. Dexmedetomidine infusion is associated with enhanced renal function after thoracic surgery. J Clin Anesth. 2006;18(6): $422-426$.

\section{Publish your work in this journal}

Therapeutics and Clinical Risk Management is an international, peerreviewed journal of clinical therapeutics and risk management, focusing on concise rapid reporting of clinical studies in all therapeutic areas, outcomes, safety, and programs for the effective, safe, and sustained use of medicines. This journal is indexed on PubMed Central, CAS,
EMBase, Scopus and the Elsevier Bibliographic databases. The manuscript management system is completely online and includes a very quick and fair peer-review system, which is all easy to use. Visit http://www.dovepress.com/testimonials.php to read real quotes from published authors.

Submit your manuscript here: http://www.dovepress.com/therapeutics-and-clinical-risk-management-journal 